\title{
On giving preference to prior volunteers when allocating organs for transplantation
}

\author{
Raanan Gillon Imperial College Health Service and St Mary's Hospital Medical School, London University
}

In this issue of the journal Rupert Jarvis argues for a simple idea - a 'modest proposal' - that he believes will radically increase the supply of organs for transplantation (1). Given the existing shortage of donor organs for transplantation it would be entirely just, he reasons, for our society to give priority for receipt of organs for transplantation to those patients who had previously volunteered to donate their own organs. Once such a scheme was promulgated, the incentive to volunteer as an organ donor would, he plausibly argues, become very great indeed, and thus the supply of organs would become much larger than at present.

Many positive benefits of such a scheme are claimed by $\mathrm{Mr}$ Jarvis. It meets, he argues the Aristotelian criterion for distributive justice in that people are treated un-equally only if there are morally relevant differences between them; including the morally relevant difference of whether or not they themselves had been prepared to contribute to the scheme from which they wish to benefit. The scheme, he says, tends to promote altruism - 'albeit self-regarding' altruism. Moreover, aligning the individual's self-interest with the public good tends to promote both the satisfaction of individual selfinterest and the public good, both of which are morally desirable. The scheme respects the autonomy of donors with minimal coercion. And if sufficient organs are donated as a result of the scheme's success, it could also make possible organ transplants for those who had not previously volunteered their own organs.

If one pursues the moral analysis using the Beauchamp and Childress 'four principles', along with consideration of their scope of application, Mr Jarvis's 'modest proposal' certainly does seem to meet some standard moral requirements.

As he points out, respect for donors' autonomy is achieved in that donors are not coerced into volunteering their own organs. His proposal does not even involve the element of coercion by inertia that a presumed consent law would allegedly entail. People are simply positively rewarded for volunteering their organs and thus behaving in a way that is both of potential benefit to themselves and also of potential benefit to others.
So far as the autonomy of potential recipients is concerned, all would retain their right to have their autonomy respected if they refused treatment. As for their preference to be given treatment by organ transplant should they need it, suffice it here merely to assert that this is not strictly an issue of autonomy - (literally self rule). Rather it is an issue of beneficence, and more specifically of the just distribution of scarce medical benefits, to be addressed below, in relation to justice.

So far as the scope of autonomy is concerned, familiar problems would arise in an unfamiliar context - notably the context of inadequatelyo autonomous potential organ donors. These would comprise, for the most part, either inadequately autonomous children, or adults who are inadequately autonomous as a result of mental and or neurological disorder or immaturity. One way of resolving these problems would be to exempt all inadequately autonomous people from the proposed scheme.

Alternatively, some scheme could be devised to make possible (and easy) proxy advance donations by parents on behalf of their children, so long as the children were deemed too young to make autonomous prior donations themselves. Perhaps this could be done at the time of infant immunisations, which in developed countries, at least, almost all infants have. While any such discussion is likely to be distasteful and unpleasant to both health care workers and parents - who wants to think about an infant's possible death - the positive potential benefit to the child could be emphasised as an excellent reason for the parents to add their child to the pool of possible organ donors. (At the same time the parents might be encouraged to review their own organ donor status, again in the interests not only of concern for others but also in their own interests should they ever need an organ transplant).

Later, a routine invitation to volunteer as a potential organ donor could be sent to each young person on his or her sixteenth birthday. An additional and relatively simple method for contacting all adults from the age of sixteen upwards would be to add a question about organ donation onto the voters' registration form that all households in the $\mathrm{UK}$ are legally 
obliged to complete in order to maintain the electoral register. This would ensure that the vast majority of adults would be given regular opportunities and encouragement to 'opt in' to a scheme that is of social as well as personal benefit - what current business jargon calls a 'win-win situation'.

More complicated would be the development of a scheme for proxy donation of their organs by adults who were deemed incompetent to make autonomous advance donations because of sufficiently severe mental and or neurological disorder or immaturity. Again, one solution would be to exempt this group from the scheme. Alternatively, health care workers, in co-operation with other carers, could be empowered to make decisions to volunteer their organs on behalf of mentally incapacitated adults. Such proxy decisions could be made, in the large majority of cases, on the straightforward grounds that they were clearly likely to be in the medical best interests of the person thus 'volunteered', (by placing that person in the priority group for receipt of transplant organs should a transplant be necessary), without causing any significant harm.

So far as 'substituted judgment' is concerned, unless there were valid prior directives to the contrary, it could reasonably be assumed that the person concerned, were he or she adequately autonomous, would probably volunteer to be an organ donor, given the existence of such a scheme. This claim is made on the assumptions (a) that such volunteering would be in the person's self-interest it in no way relies on any assumption of altruism; and (b) that the large majority of people would autonomously choose in their own best interests if there were no countervailing moral objections.

What about benefits and harms? So far as volunteers are concerned there seems little doubt that they would benefit from such a scheme. Furthermore, if the plausible prediction of a considerable increase in organ donors were borne out in practice, then there would be a considerable increase in overall benefits for people who could benefit from transplantation but who currently do not benefit because of the shortage of supply. Indeed if the rejuvenated supply of organs became sufficiently augmented by the scheme even non-volunteers for organ donation would benefit.

In the absence of such an enormous increase in organ supply, however, the non-volunteers would clearly lose out and stand to benefit less than at present, if the proposal were accepted. They would be deliberately put at the bottom of the queue for transplanted organs, even in particular situations where their need for, and the extent and probability of their potential benefit from, such transplants would be greater than the needs and benefits of the pre-volunteers who would be given priority.

Here seems to be the Achilles heel of Mr Jarvis's proposal. For even if such non-volunteers can properly be said to have only themselves to blame for their predicament; even if they can properly be said to have deliberately and autonomously made their choice and rejected the opportunity to give themselves priority for receipt of transplanted organs; even if they can properly be said to have been selfish, and or inconsiderate and or foolish, even immoral, in refusing to pre-volunteer their own organs, nonetheless there is an important countervailing moral tradition in medicine. It is that patients should be given treatment in relation to their medical need, and that $\triangle$ scarce medical resources should not be prioritised on $\nRightarrow$ the basis of a patient's blameworthiness. This moral tradition of medicine is partly an aspect of the medicomoral obligation of medical beneficence - doctors have obligations to try to provide medical benefits to all their patients who are in medical need, and they should not deny such benefits on the grounds of a i patient's past or present fault. It is also a matter of $\vec{A}$ justice - doctors should not use fault as a criterion for just distribution of scarce medical resources.

$\mathrm{Mr}$ Jarvis says that his proposal accords with $\mathrm{O}$ Aristotle's formal principle of justice, and no doubt it does, for in some moral contexts undoubtedly past fault, past decisions, past choices, do indeed justify treating people as unequals for the purposes of $\cong$ justice. But the Aristotelian formal principle of justice (equals should be treated equally, unequals of unequally in proportion to the morally relevano inequality) is compatible with a variety of substantive principles of justice. Fault, past or present, is wide rejected as a 'morally relevant inequality' by currently accepted substantive principles of distributive justice for scarce medical resources. Attractive though Mr Jarvis's proposal may otherwise be, it does seem to entail reversing this moral norm. If past or present fault thus became an accepted criterion for distributive justice for scarce medical resources, a very steep 'logical slippery slope' would have been created.

If the fault and/or inconsiderateness of not previously volunteering his or her organs for transplantation were to justify withholding scarce life-saving medical resources from a patient, then all other prior faults and inconsiderateness of equal or greater weight could, logically, also be regarded as morally relevant and potentially justificatory for withholding scarce life-saving medical resources from patients. Such a prospect hardly bears contemplation. While fault may well be an entirely 'morally relevant' criterion for legal justice, it seems highly likely to create far more social harm than benefit if it is used as a criterion for distributing scarce life-saving medical resources. Alas, Mr Jarvis's otherwise apparently admirable 'modest proposal' seems likely to succumb to this major objection (1).

\section{Reference}

(1) Jarvis R. Join the club: a modest proposal to increase availability of donor organs. Fournal of medical ethics 1995; 21: 199-204. 